University of Wollongong

Research Online

Faculty of Engineering and Information

Faculty of Engineering and Information

Sciences - Papers: Part B

Sciences

2017

\title{
Review on Design and Control Aspects of Robotic Shoulder Rehabilitation Orthoses
}

\author{
Aibek Niyetkaliyev \\ University of Wollongong, asn936@uowmail.edu.au \\ Shahid Hussain \\ University of Wollongong, shussain@uow.edu.au \\ Mergen HMcGill University, Ghayesh \\ University of Adelaide, mergen.ghayesh@adelaide.edu.au \\ Gursel Alici \\ University of Wollongong, gursel@uow.edu.au
}

Follow this and additional works at: https://ro.uow.edu.au/eispapers1

Part of the Engineering Commons, and the Science and Technology Studies Commons

\footnotetext{
Research Online is the open access institutional repository for the University of Wollongong. For further information
} contact the UOW Library: research-pubs@uow.edu.au 


\title{
Review on Design and Control Aspects of Robotic Shoulder Rehabilitation Orthoses
}

\begin{abstract}
Robotic rehabilitation devices are more frequently used for the physical therapy of people with upper limb weakness, which is the most common type of stroke-induced disability. Rehabilitation robots can provide customized, prolonged, intensive, and repetitive training sessions for patients with neurological impairments. In most cases, the robotic exoskeletons have to be aligned with the human joints and provide natural arm movements. This is a challenging task to achieve for one of the most biomechanically complex joints of human body, i.e., the shoulder. Therefore, specific considerations have been made in the development of various existing robotic shoulder rehabilitation orthoses. Different types of actuation, degrees of freedom (DOFs), and control strategies have been utilized for the development of these shoulder rehabilitation orthoses. This paper presents a comprehensive review of these shoulder rehabilitation orthoses. Recent advancements in the mechanism design, their advantages and disadvantages, overview of hardware, actuation system, and power transmission are discussed in detail with the emphasis on the assisted DOFs for shoulder motion. A brief overview of control techniques and clinical studies conducted with the developed robotic shoulder orthoses is also presented. Finally, current challenges and directions of future development for robotic shoulder rehabilitation orthoses are provided at the end of this paper.
\end{abstract}

\section{Keywords}

review, control, design, aspects, orthoses, robotic, shoulder, rehabilitation

\section{Disciplines}

Engineering | Science and Technology Studies

\section{Publication Details}

Niyetkaliyev, A., Hussain, S., Ghayesh, M. H. \& Alici, G. (2017). Review on Design and Control Aspects of Robotic Shoulder Rehabilitation Orthoses. IEEE Transactions on Human-Machine Systems, 47 (6), 1134-1145. 


\title{
Review on Design and Control Aspects of Robotic Shoulder Rehabilitation Orthoses
}

\author{
Aibek S. Niyetkaliyev, Member, IEEE, Shahid Hussain, Mergen H. Ghayesh, and Gursel Alici
}

\begin{abstract}
Robotic rehabilitation devices are more frequently used for the physical therapy of people with upper limb weakness which is the most common type of stroke-induced disability. Rehabilitation robots can provide customized, prolonged, intensive and repetitive training sessions for patients with neurological impairments. In most cases, the robotic exoskeletons have to be aligned with the human joints and provide natural arm movements. This is a challenging task to achieve for one of the most biomechanically complex joint of human body, the shoulder. Therefore, specific considerations have been made in the development of various existing robotic shoulder rehabilitation orthoses. Different types of actuation, degrees of freedom (DOFs) and control strategies have been utilized for the development of these shoulder rehabilitation orthoses. This paper presents a comprehensive review of these shoulder rehabilitation orthoses. Recent advancements in the mechanism design, their advantages and disadvantages, overview of hardware, actuation system and power transmission are discussed in detail with the emphasis on the assisted DOFs for shoulder motion. A brief overview of control techniques and clinical studies conducted with the developed robotic shoulder orthoses is also presented. Finally, current challenges and directions of future development for robotic shoulder rehabilitation orthoses are provided at the end of the paper.
\end{abstract}

Index Terms - stroke, shoulder rehabilitation, robotic orthoses, exoskeleton, mechanism design, actuation, control strategies.

\section{INTRODUCTION}

$\mathrm{T}$ HE proper functionality of shoulder is crucial for effective use of human arm during activities of daily living (ADL). Unfortunately, the weakness and loss of upper limb motor control is a common neurological impairment arising from stroke, with $88 \%$ [1] (77.4\% [2]) of stroke survivors running into some degree of functional limitations of upper limb. The exhausting and laborious conventional physical therapies are initiated in clinics to maximize potential for motor recovery [3-5]. Moreover, the intricate anatomy of upper limb makes its recovery more complex in comparison to lower-limb rehabilitation.

However, recent developments in technology enabled robotic devices to assist stroke patients with upper limb disabilities. These robotic devices can provide task oriented,

A. S. Niyetkaliyev, S. Hussain and G. Alici are with the School of Mechanical, Materials and Mechatronic Engineering, University of Wollongong, NSW, Australia (Email: shussain@uow.edu.au).

M. H. Ghayesh is with the School of Mechanical Engineering, University of Adelaide, SA, Australia. prolonged, accessible, repetitive and intensive physical therapy [6-9]. Therefore, these upper limb rehabilitation robots have made it possible to improve the motor recovery in stroke survivors while reducing the burden on physical therapists $[8$, 9].

Upper limb rehabilitation robots [10-16] can be divided into two types: exoskeletons or orthotic systems where the robot's joints are designed to correspond with the human joints and end-effector based devices that are connected to the arm segment at one point with the axes that are usually not aligned with the joints of the subject. Compared with end-effector based robots, exoskeletons are more complex in terms of mechanism design and actuation as well as control. The adjustability of robotic orthoses to human body is more difficult and can cause joint axes misalignments which in turn lead to undesirable interaction torques. This is a challenging task to consider when designing robotic orthosis for the shoulder complex, which is composed of several bones and can perform complex motions with various degrees of freedom (DOFs). Numerous groups of researchers have designed and built different robotic devices with various mechanical advancements for shoulder complex rehabilitation.

The purpose of this paper is to review the design and control aspects of existing robotic orthoses for shoulder rehabilitation and to discuss some areas for future development. To limit the scope of this work, the passive robotic orthoses for shoulder rehabilitation (such as WREX [17] and Dampace [18]) and the end-effector-based robotic devices developed for shoulder rehabilitation (e.g. MITMANUS [19]) are not included in this review. Moreover, although most of the upper limb exoskeletons reviewed in this paper also assist other parts of arm such as elbow, forearm and wrist, the discussion of these upper limb segments is excluded from this review. To increase the reliability of the reviewed papers only papers published in peer review journals and highly cited or selected recent conference papers are considered in this paper.

\section{BIOMECHANICS OF SHOULDER COMPLEX}

The biomechanics of shoulder complex, well studied and described in the literature [20-25], is briefly presented in this section since the knowledge of the anatomy and the movement characteristics of shoulder is an essential step towards the development of robotic shoulder rehabilitation orthoses.

The human shoulder shown in Fig. 1 is an integrated complex with three bones (clavicle, scapula and humerus) and 
four independent joints. The sternoclavicular (SC) joint connects the clavicle to the thorax, the acromioclavicular (AC) joint connects the scapula to the clavicle, the scapulothoracic (ST) articulation describes scapula motion over the thorax and the glenohumeral $(\mathrm{GH})$ joint, also referred as shoulder joint, connects the humerus to the scapula. The former three joints compose the closed-kinematic chain called shoulder girdle. The glenohumeral joint is commonly oversimplified as a "ball and socket type" joint with three DOFs. It is formed by the "socket" of the female part of the scapula, also called glenoid cavity, and the upper part of the humerus, named humeral head $(\mathrm{HH})$.

The integrated motion between scapulothoracic and glenohumeral joint, which results in the displacement of the humerus, is usually referred as scapulohumeral ( $\mathrm{SH}$ ) rhythm or shoulder rhythm $[26,27]$. Therefore, the position of the centre of glenohumeral (CGH) joint, also referred as instantaneous centre of rotation (ICR) of the shoulder joint, is dynamic and it shifts due to interactions with the shoulder girdle [28]. Moreover, there are also individual differences in anatomical characteristics and joint kinematics.

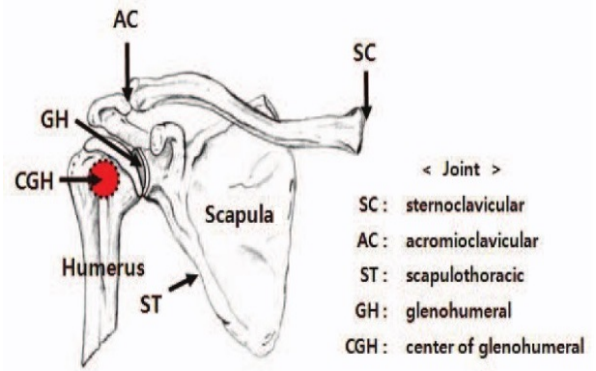

Fig. 1. Structure of shoulder complex [29].

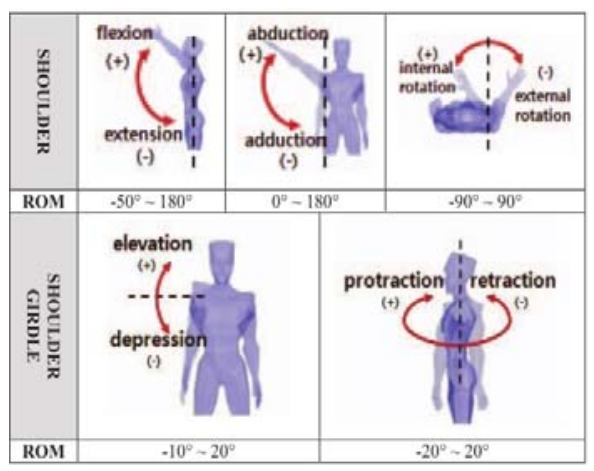

Fig. 2. Movements of shoulder complex [29].

The three rotational movements of the shoulder, shown in the upper part of Fig. 2, can be described with the following terms: flexion/extension (F/E), abduction/adduction (A/A) and internal/external rotation (IR/ER). The shoulder girdle's motion has 4-DOFs overall but is generally described by two translational movements as shown in the lower part of Fig. 2: elevation/depression (E/D) and protraction/retraction $(\mathrm{P} / \mathrm{R})$ [30]. Hence, with three rotational and two translational the simplified model of the shoulder complex has 5-DOFs.

\section{MECHANISM DESIGN}

Since the human shoulder complex is biomechanically ingenious, specific design considerations have to be made when developing robotic shoulder orthoses. In this section, a brief review of the state-of-the-art robotic shoulder rehabilitation orthoses with their mechanism design, number of DOFs for shoulder and actuation types is presented.

\section{A. Robotic Shoulder Orthoses Powered by Electric Actuators}

A robotic orthosis ARMin III (Fig. 3(a)) has been developed at the ETH Zurich for upper limb rehabilitation from its previous versions ARMin I [31] and ARMin II [32]. It was the first exoskeleton robot to be commercially available, now known as Armeo Power (Hocoma product), which has been used in several hospitals in Europe and US [33]. ARMin III exoskeleton has 6-DOFs with 3 actuated DOFs for shoulder. The joints (revolute and prismatic) of this heavy back-drivable robotic orthosis with rigid links are actuated by DC motors with harmonic drive (HD) gearbox. The mechanical end stops, spring and laser pointers are used to increase the safety, compensate the weight and ease the patient-positioning, respectively. Furthermore, this robotic device can be easily adjusted from left to right side which makes it operationally efficient in clinics. However, the prismatic joint that lifts the whole structure takes a lot of space and complicates the actuation of the robot. The vertical motion of $\mathrm{CGH}$, which is modeled as a rotational movement without any horizontal translation, is only achievable along with the arm elevation which limits training of some shoulder movements and causes misalignments between the patient and robot axes [34].

On the other hand, the specific shoulder motions in vertical translational direction, limited with ARMin III, can be trained with another 6-DOFs robotic shoulder orthosis called Maryland-Georgetown-Army (MGA) exoskeleton, shown in Fig. 3(b) [39]. The shoulder complex in this robotic device is enclosed with circular rigid links with three revolute joints modelling a "ball-and-socket" joint. Moreover, this exoskeleton is among the first to take scapula motion into account considering shoulder girdle's elevation and depression [36]. However, the use of the additional motor (mounted as other motors directly on joint) that lifts the mechanism upwards could lead to joint axes misalignments and make this non-back-drivable robot more expensive and hazardous.

A robotic 7-DOFs cable-actuated anthropomorphic exoskeleton CADEN-7, shown in Fig. 3(c), has been developed for upper extremities rehabilitation with 3-DOFs for glenohumeral joint in the University of Washington, Seattle [37]. The advantages of this device are low inertia, negligible backlash, high stiffness links, mechanical stops, emergency switches and driven pulleys that make it possible to distantly locate the actuators reducing the torques on the robot framework. The drawback of this actuation system is that it constraints the transportability and adjustability of the exoskeleton. Moreover, the electric motors used to actuate this high power robotic orthosis are heavy. The succeeding twoarm exoskeleton system of CADEN-7 is named EXO-UL7 (developed in USCS) [40].

Another 5-DOF robotic orthosis developed for upper arm 


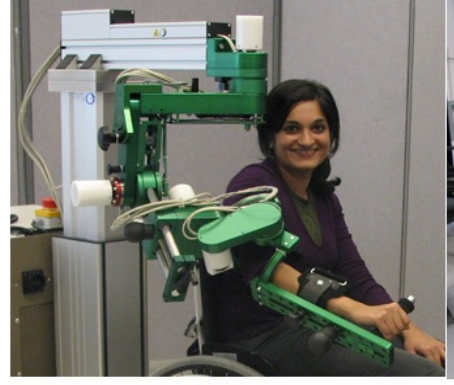

(a)

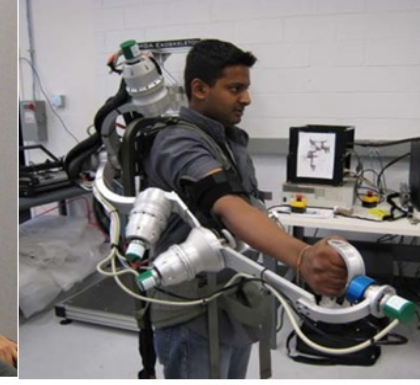

(b)

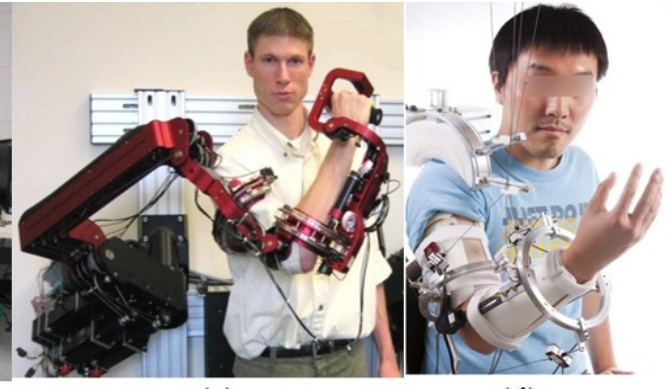

(c)

(d)

Fig. 3. (a) ARMin III [34], (b) MGA [36], (c) CADEN-7 [37], (d) CAREX [38].

rehabilitation is called Cable-driven ARm EXoskeleton (CAREX) (Fig. 3(d)) [41]. Instead of the rigid links, this robotic orthosis has three lightweight cuffs attached around the shoulder, the upper arm and the forearm, respectively. The limb parts are moved by cables passing through the cuffs that are driven by motors. Four such cables are used for three rotational DOFs of shoulder joint. Due to the use of these cables, the motors are placed away from the human body. This actuation concept was adopted from the wearable haptic device on a human arm [42]. The rotary encoder and sensors in CAREX are used to determine the orientation of glenohumeral joint. The major advantages of this device include a reduced overall weight $(1.55 \mathrm{~kg})$ and loads on arm segments. The exoskeleton is not required to be aligned with human joint axes since there are no joints and links. The cables go from one segment of the arm to another without the need for independent sets of cables and there are no restrictions on natural arm movements [38]. An approach for real-time measurement of CGH with CAREX was presented in [43]. Nonetheless, more accurate estimation of the CGH and workspace analysis are still required to establish proper kinematic model.

The IntelliArm is a robotic orthosis that has more DOFs (7 active (i.e. actuated) and 2 passive) than most of the exoskeletons for upper limb rehabilitation and can independently and synchronically control the shoulder, elbow, and wrist [44]. In this exoskeleton, all 3-DOFs of shoulder joint and the vertical shift of GH joint are provided with four active DOFs whereas two passive DOF are used for anteroposterior and mediolateral displacement of $\mathrm{GH}$ joint. Altogether the use of these active/passive joints can thoroughly replicate the shoulder movements, and the exoskeleton's rotation axes can be aligned with the patient's shoulder taking into account scapular and body movements [45]. Shoulder's reaction torques and forces are measured using a torque/force sensor fixed to the shoulder. The actuation is provided through cable transmission by motors placed remotely from the patient's head. A circular guide and a cable mechanism are used for shoulder's twisting joint (internal/external rotation). Even though this exoskeleton is closely aligned with the shoulder, the heavy and expensive high-torque motors hinder its use in clinical settings [46]. A similar mechanism design with active shoulder girdle control was proposed in [29].

The National Taiwan University Hospital-ARM (NTUHARM) is an orthosis with seven actuated DOFs, six of which ( 1 prismatic and 5 rotational) account for the shoulder. This redundantly actuated robotic orthosis is powered by using brushed DC motors and assists all five shoulder DOFs [47]. Another electrically actuated compatible 3-DOFs shoulder exoskeleton translates two axes of shoulder joint to adapt the CGH position describing its mechanical motion using the sagittal, frontal, transverse, and rotation (SFTR) system [48].

One of the most advanced mechanism designs for shoulder rehabilitation is presented in MEDARM exoskeleton that fully covers all shoulder rotational and translational motions [49]. However, according to the authors' knowledge, no real prototype of this robotic rehabilitation device with proposed electrical type of actuation system is built. ASSISTON-SE is another proposed exoskeleton for shoulder rehabilitation that has five active DOFs and a passive slider to fully assist all shoulder motions [50]. Another recent exoskeleton with three parallel linear electric actuators (3-DOFs) for the shoulder joint and a passive slip interface (2-DOFs) for the shoulder girdle is developed in the Arizona State University [55].

Some other robotic shoulder rehabilitation orthoses powered by electromagnetic actuators are L-EXOS [56], SUEFUL-7 [57], ALEx (commercial product developed at PERCRO lab) [58], KINARM (BKIN Technologies) [59], ETS-MARSE [60], ARAMIS [61], ARMOR [62], IKO (hybrid actuation with electric motors for shoulder) [63], mobile 3-DOFs motion assist exoskeleton [64], 5-DOFs robotic exoskeleton in SCUT lab [65], Sensoric Arm Master (SAM) [66], Shoulder Rehabilitation Robot (SRR) [67], ABLE [68] and MULOS [69].

\section{B. Shoulder Orthoses Powered by Pneumatic Actuators}

A pneumatically actuated lightweight exoskeleton, called Robotic Upper Extremity Repetitive Therapy (RUPERT), was developed for use in physical therapy by researchers at Arizona State University [70]. The latest version of this wearable 5-DOFs robotic orthosis named RUPERT IV (Fig. 4 (a)) has gone through several improvements over almost tenyear period [71]. This portable back-drivable robot is driven by unpaired compliant pneumatic artificial muscles (PAM) with a high power to weight ratio, also referred as McKibben muscles. PAM can contract or extend using the compressed air. Compared to the previous designs, RUPERT IV has added1-DOF for shoulder joint providing shoulder external rotation and elevation [51]. Larger torques can be achieved at shoulder joint by increasing the pressure or the diameter of air muscles [72]. Composite materials are used to reduce the overall weight of this rehabilitation robot that can be worn while standing or sitting. Another important design 


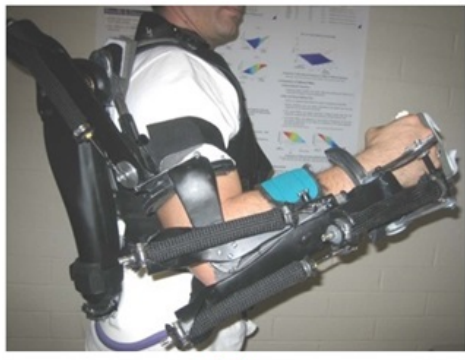

(a)

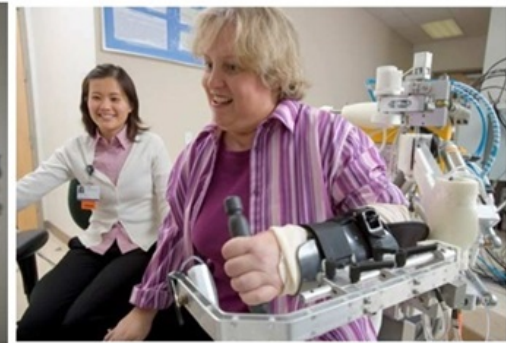

(b)

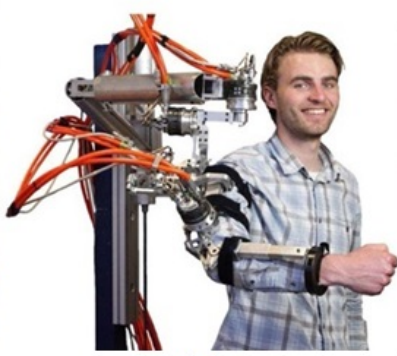

(c)

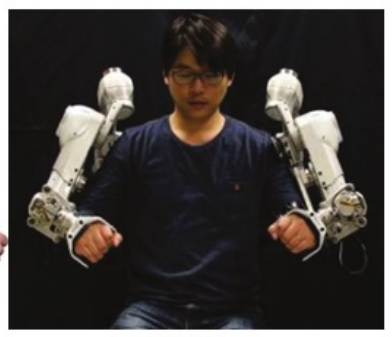

(d)

Fig. 4. (a) RUPERT IV [51], (b) Pneu-WREX [52], (c) LIMPACT [53], (d) HARMONY [54].

characteristic of this exoskeleton with adjustable lengths of arm segments is that it was developed without gravity compensation promoting practices in a natural setting [70]. However, pneumatic artificial muscles for each joint can only provide unidirectional actuation. Moreover, the restrictions at shoulder joint in this device limit the full range of motion of the human arm.

Pneu-WREX (Fig. 4(b)) developed at the University of California [73] based on passive exoskeleton T-WREX [74] is a lightweight pneumatically driven robotic orthosis for physical therapy of the upper limb. Pneu-WREX, using pneumatic actuators and a spring to balance its own weight, generates a wide range of active forces to provide naturalistic arm movements and includes a number of safety features [52]. Four out of five DOFs of this device are designed for shoulder complex [72]. Each of these DOFs is actuated by a lowfriction pneumatic cylinder.

Biomimetic Orthosis for the Neurorehabilitation of Elbow and Shoulder (BONES) based on a parallel mechanism is a pneumatically actuated exoskeleton with 3-DOFs for shoulder motion [75]. A humanlike musculoskeletal shoulder robot actuated by the pneumatic artificial muscles, assembled like natural human muscles, to replicate complex shoulder movements is developed by the researchers from Osaka University [76]. Some other robotic shoulder rehabilitation orthoses powered by pneumatic actuators are SRE (using PAM) [77], "Muscle Suit" (McKibben muscles) [78], ZJUESA [79], KIST (pneumatic and electric brake actuators) [80], 7-DOFs wearable robotic arm [81] and an exoskeleton for shoulder elevation [82].

\section{Robotic Shoulder Orthoses Powered by Hydraulic Actuators/Series Elastic Actuation}

A compliantly actuated robotic exoskeleton LIMPACT (see Fig. 4(c)) has been developed for use in stroke therapy which consists of four rotational series elastic hydraulic motors and torsion springs [83]. The mechanical design of this robotic orthosis with 3-DOFs (actuated) at the shoulder joint is based on a passive exoskeleton called Dampace [18], the predecessor of LIMPACT, in which the Bowden cables and disk brakes were used instead of hydro-elastic actuation. The model of LIMPACT exoskeleton is divided into four sub-models with a total of 18 rigid parts combined by 20 revolute joints [53]. Both Dampace and the LIMPACT have passive self-aligning shoulder mechanisms and take into account the translational DOFs in the shoulder. Also, LIMPACT is able to align the shoulder without a controller, and a motor passively balancing the system with gravity compensation [53]. However, such passive aligning mechanisms are confined in supporting patients during GH mobilization trainings [50]. Moreover, this robotic device currently can only be used in research facilities due to the expensive installation of its actuation system which has a large and unsafe hydraulic pump [53]. Another example of a hydraulically actuated upper limb exoskeleton with 3DOFs for shoulder is called Sarcos Master Arm [84].

A two-armed exoskeleton called HARMONY (Fig. 4(d)) with series elastic actuators at every joint has recently been developed at the ReNeu Robotics Lab, University of Texas [54]. It provides 5-DOFs (active) for each shoulder: 3-DOFs rotations at the GH joint and 2-DOFs for the shoulder girdle movement. The developed shoulder girdle mechanism is able to change circular motions in different directions with the designed parallelogram and rotary joint. HARMONY is a stationary upper limb exoskeleton that connects to human body at three places on each side and can be adjusted to fit various body sizes. However, it could still be considered as a heavy and large robotic orthosis with complex configuration.

Another device designed for post-stroke shoulder rehabilitation with series elastic actuation is a wearable cabledriven compliant shoulder brace [85]. It is a deformable and lightweight elastic device with two Bowden cables used for power transmission. Encoders and IMU (Inertial Measurement Unit) sensors are used to measure cable lengths and orientation offsets in real time, respectively. However, this soft orthosis has a very limited mobility with just 1-DOF for shoulder abduction-adduction movement. Some other robotic shoulder rehabilitation orthoses with series elastic actuation or elastic elements found in the literature are intrinsically compliant continuum shoulder exoskeleton [86], wearable shoulder exoskeleton [87] and MUNDUS [88].

Summary: Some of the above reviewed robotic shoulder orthoses consider translational motions of shoulder girdle by translating one (ARMin II-III) or two (3-DOFs compatible exoskeleton [48]) axes of shoulder joint with coupling mechanism or by designing a special mechanical linkage [64]. The shoulder girdle movements can also be assisted using one (MGA, Pneu-WREX, exoskeleton in [89]) or more (MEDARM, NTUH-ARM, HARMONY, musculoskeletal shoulder [76]) additional active DOFs, passive self-alignment (Limpact, SUEFUL-7) or with the use of both active and passive DOFs (IntelliArm, IKO, ASSISTON-SE). It may be argued that the costs, weight and control complexity of such mechanical advancements are not worth the benefits obtained with them during the physical therapy [90]. For example, in 
exoskeletons such as CADEN-7, L-EXOS and CAREX, these translational shoulder movements are compensated by body movements with fixed CGH.

Apart from the consideration of shoulder girdle movement, some other advantages of the main existing robotic shoulder orthoses are reduced weight (CAREX, RUPERT IV), availability for both arms (ARMin III, EXO-UL7, IntelliArm, HARMONY) and gravity compensation (e.g. Pneu-WREX, LIMPACT, L-EXOS, MGA). Singular positions (singularities) that can occur in the mechanisms during the movement of robotic structures is another important consideration taken into account in CADEN-7, L-EXOS, MGA and exoskeleton in [89] (by tilting the position of the motors), BONES (by restricting the workspace), NTUH-ARM (by adding extra DOF) and MEDARM (designed so that singularities occur further from the normal workspace). In mechanisms with a passive self-alignment, singularities can occur within the workspace [89]. The majority of the existing shoulder rehabilitation devices have been actuated with conventional bulky motors due to the ease of their control, availability and low cost. Cables and pulleys are used for power transmission to locate the heavy motors away from a human body. On the other hand, lightweight PAMs have a higher power to weight and power to volume ratios but are more difficult to control due to the structured nonlinearities in their dynamic model. The hydraulic actuators have even a higher power to weight ratio than PAMs but their installation in most cases is problematic and raises health and safety problems due to the nature of liquids used. To replicate the natural movements of human arm, compliant actuators with series elastic elements and other deformable actuators can also be used. Moreover, the combined types of actuation with improved functional capabilities and back-drivable transmissions can be developed to deliver more efficient and comfortable use of robotic shoulder orthoses.

\section{Control Strategies}

Control strategies for the robotic upper limb rehabilitation orthoses are developed to repetitively guide the patients' limbs on anatomically and ergonomically feasible trajectories so that the patients can regain muscular strength. Development of these control strategies has also been an important area of research in the robot upper limb rehabilitation [47, 65, 91-96].

The control strategies for upper-limb rehabilitation robots can be classified in different ways. In one of the recent reviews on upper-limb exoskeletons, the authors categorized control methods based on input information (human biological signal, non-biological signal, platform independent method), output of the controller and controller architecture [10]. In [12], the authors considered "high-level" (assistive control, challenge-based control, haptic stimulation and non-contacting coaching) and "low-level" (impedance control and admittance control) control algorithms used by robotic devices in upperlimb rehabilitation, following the terminology proposed in [91]. In short, the former control strategies are directly intended to raise motor unit plasticity while the later regulate parameters such as impedance, admittance, force and position [12]. In [95], the exoskeleton control systems were classified based on the model (dynamic and muscle), the hierarchy (task, high and low levels), the physical parameters (position, torque/force and force interaction) and the usage (virtual reality, teleoperation and gait). Moreover, the exoskeletons can also be controlled in different modes: active assisted, active unassisted, passive and resistive [97]. Another alternative classification (defined in [98] based on [96]) of control strategies for robot-aided rehabilitation includes three modes: assistance (passive, triggered passive and partially assistive control), correction (tunneling and coordination control) and resistance.

Most of the controllers for existing upper limb exoskeletons are assistive, which means the controller helps the patients to move their disabled arm to accomplish desired movements imitating therapist's rehabilitation assistance [91]. Different control techniques are used in recent robotic orthoses for shoulder rehabilitation to implement this concept.

Assist-as-Needed (AAN) control is an active assisting training paradigm in recent rehabilitation practices supporting patient's motion with the minimal amount of assistance. The concept behind the development of AAN algorithms is to modify the robotic assistance according to the disability level and effort put by the patients during the rehabilitation process. If the patients show some progress and recovery by incorporating their muscular strength, the robotic assistance is reduced and vice versa. This control strategy, in which robotic device does not need to operate for the full duration of the motion, increases the patient's muscle activity being one of the promising control technique in recovery. Commonly, such control algorithms incorporate the desired trajectory with a resistance field that estimates the required supportive action. Therefore, impedance schemes and adaptive controllers are usually applied within AAN control paradigm [99]. A number of AAN control strategies has been developed and implemented for shoulder rehabilitation robots as follows.

Adaptive "assist-as-needed" and force field control methods have been used for CAREX orthosis to control the cable tension [38]. An "assistance-as-needed" controller that can be adapted during the action was developed for Pneu-WREX exoskeleton with non-linear force controller for pneumatic actuators [52]. An active assisted mode has also been realized in LIMPACT orthosis. Its overall control architecture consists of a torque and an impedance controller. The inner-loop torque controller includes a Smith predictor with a lead-lag filter and the outer-loop impedance controller incorporates a gravitation vector with a state feedback controller [53]. An assistive control system has been developed for NTUH-ARM exoskeleton based on the human arm dynamics obtained with a pair of 6-axis force/torque sensors and gravity compensation [47]. To ensure the efficacy of the proposed control strategy, the authors made the Lyapunov stability analysis prior to its experimental evaluation [47].

Most of the shoulder robots (L-EXOS, MGA, SRE to name a few) use impedance or/and admittance control schemes with joint angles and torques as control inputs to govern robotic assistance. All axes in ARMin III can be controlled with an impedance scheme in addition to computed torque (CT) control and proportional derivative (PD) control [34]. The EXO-UL7 exoskeleton system has been controlled with a linear proportional-integral-derivative (PID) controller and a PID admittance controller [100]. The control scheme that 
takes into account shoulder's scapulahumeral rhythm with coupling torque based on impedance has been developed for HARMONY exoskeleton [54]. The impedance control with ongoing feedback and a band-pass filter has been implemented in Shoulder Rehabilitation Robot (SRR) [67]. The safetyimproved nonlinear adaptive controller has been implemented in 5-DOFs upper-limb rehabilitation exoskeleton [92]. In [101], the trajectory control strategy has been presented based on human arm movements. A Lyapunov-based control strategy implemented on the shoulder robot design is presented in [102].

For RUPERT IV, a closed-loop adaptive controller has been designed for passive task training with each DOF controlled by a PID feedback controller [51]. In addition, the shoulder controller also has an Iterative Learning Controller (ILC) which can learn from the preceding estimation on individual basis and update a suitable feedforward command. A total of 13 fuzzy rules were selected to deal with the nonlinearities caused by pneumatic actuation in RUPERT IV [51]. The detailed description of implemented adaptive active-assist and cooperative modes using the controllers in RUPERT IV is given in [103].

The impedance (IMP) or admittance (ADM) control methods are usually developed without considerations of user's intention or physical condition which might be done by implementing control systems based on the electromyographic (EMG) signals [95]. The impedance control based on surface electromyographic (sEMG) signals has been implemented in shoulder robots such as ETS-MARSE [104], SUEFUL-7 [57], motion assist exoskeletons robots [64], MUNDUS [88], musculoskeletal robot arm [76] and 5-DOFs exoskeleton in SCUT lab [65].

The control algorithms used influence the performance characteristics and efficiency of the robotic shoulder rehabilitation devices. Robust and non-linear control algorithms must be developed and implemented for the new generation of robotic shoulder rehabilitation orthoses powered by intrinsically compliant actuators. With the technological developments in the brain machine interfaces, new control systems able to identify subject's intention should be considered. Advanced AAN training strategies need to be developed and the already existing AAN strategies should be clinically evaluated to provide benchmarks in the level of assistance provided to neurologically impaired patients. There are also different ways how the developed robotic shoulder orthoses could be controlled: with the mind, control panel, joystick or other interfaces.

\section{EXPERIMENTAL EVALUATIONS}

Substantial work has been done in order to advance the mechanism design and some control aspects of robotic shoulder rehabilitation orthoses. However, a few attempts have been made to test the actual performance of these orthoses in clinical settings. Nevertheless, during the last decade, the robotic shoulder exoskeletons are gradually moving from research facilities to rehabilitation settings in order to provide physical therapy to patients with strokeinduced impairments, spinal cord injuries (SCI), multiple sclerosis (MS) and cerebral palsy.
ARMin II and ARMin III have been experimentally evaluated and used in clinics more than any other robotic shoulder rehabilitation orthoses. Four chronic stroke patients (in this case more than 12 months post stroke) participated in 3-4 one hour sessions per week for 8 weeks in robot-aided therapy with ARMin II exoskeleton [105]. The main measure of treatment results was Fugl-Meyer Score of the upper extremity Assessment (FMA-UE), whereas changes in evaluations such as Wolf Motor Function Test (WMFT), Catherine Bergego Scale (CBS), Maximal Voluntary Torques (MVTs) and some questionnaire were secondary outcome measures. The experimental data showed significant positive progress of arm motor function in three out of four enrolled subjects. This formed the ground for future robot-assisted clinical studies.

A large parallel-group randomised trial was conducted in four clinical centres in Switzerland with chronic stroke patients (more than 6 months) to compare the effects of conventional therapy in neurorehabilitation and the training with robotic exoskeleton (ARMin III) [106]. After the initial surveying, eligibility assessment, randomisation and exclusions, 35 subjects were assigned to conventional and 38 to robot-assisted therapies. Both groups received 45 minutes training sessions 3 times per week for duration of 8 weeks. The primary evaluation tool (FMA-UE) was tested at different periods of the clinical trial. The findings showed that subjects who received robot-aided therapy had much greater advancements in affected arm's motor function consequently leading to a conclusion that exercises with a robotic orthosis can more effectively increase the motor function in stroke patients than traditional manual physical therapy. Another recent clinical study with ArmeoPower exoskeleton involved 35 stroke patients with hemiplegia who received 40 one hour sessions 5 times a week for 8 weeks and were assessed on FMA and Modified Ashworth (MA) scales [107]. The outcomes of this trial also indicated that use of the robotic exoskeleton can enhance motor function in upper limb rehabilitation.

Twenty chronic stroke subjects used BONES exoskeleton receiving single joint and multi-joint therapies 3 times per week for a duration of 4 weeks [108]. Box and Block Test (BBT) was the main assessment measure, while secondary outcome variables were FMA, WMFT, Motor Activity Log (MAL) and some tests on shoulder strength and speed. The findings suggest that use of a robotic device increased the motor function of patients but no major differences were reported in the outcome of multi-joint and single-joint trainings. The AAN control strategy developed in [52] has been employed in this study.

L-EXOS orthosis was evaluated with 9 chronic stroke subjects for 6 weeks. Clinical study with kinesiology assessment based on EMG analysis has been conducted and evaluation measures such as FMA and MA has been performed [109]. As a result, the statistical improvements of measured variables (shoulder motion parameters) with some correlations are reported. The favorable results were attained with the NTUH-ARM exoskeleton in clinical trials with six stroke patients verifying the effectiveness of the AAN control [47]. Fourteen stroke subjects with hemispheric lesions were enrolled in clinical study with 6-DOFs dual exoskeleton robot 
Table I. Summary Table of Existing Robotic Shoulder Rehabilitation Orthoses

\begin{tabular}{|c|c|c|c|c|c|c|c|c|}
\hline $\begin{array}{l}\text { Device } \\
\text { (based on) }\end{array}$ & $\begin{array}{c}\text { UL } \\
\text { segment }\end{array}$ & $\begin{array}{c}\text { DOF } \\
\text { Total/Shoulder }\end{array}$ & $\begin{array}{c}\text { SG } \\
\text { motion }\end{array}$ & Type & $\begin{array}{l}\text { Control } \\
\text { method }\end{array}$ & Advantages & Disadvantages & $\begin{array}{c}\text { Clinical } \\
\text { Study (sp) } \\
\end{array}$ \\
\hline $\begin{array}{l}\text { ARMin III* } \\
\text { ArmeoPower }\end{array}$ & $\mathrm{S}+\mathrm{E}+(\mathrm{W})$ & $6 \mathrm{a} / 3 \mathrm{a}$ & $\mathrm{E} / \mathrm{D}-\mathrm{c}$ & $\mathrm{e}$ & $\begin{array}{l}\text { IMP, PD, } \\
\text { CT }\end{array}$ & $\begin{array}{l}\text { Back-drivable, available for both arms, no extra actuators } \\
\text { for SG aligning }\end{array}$ & $\begin{array}{l}\text { High inertia, simple model of (limited) shoulder } \\
\text { motion }\end{array}$ & yes \\
\hline $\begin{array}{l}\text { EXO-UL7 } \\
(C A D E N-7)^{*}\end{array}$ & $\mathrm{~S}+\mathrm{E}+\mathrm{W}$ & $7 \mathrm{a} / 3 \mathrm{a}$ & no & $\mathrm{e} / \mathrm{c}-\mathrm{d}$ & $\begin{array}{l}\text { PID, ADM, } \\
\text { EMG }\end{array}$ & $\begin{array}{l}\text { Low inertia, negligible backlash, high stiffness links, } \\
\text { mechanical stops, emergency switches and driven pulleys, } \\
\text { available for both arms, KS considered }\end{array}$ & $\begin{array}{l}\text { Constrained in the transportability and adjustability, } \\
\text { motors are heavy and big }\end{array}$ & yes \\
\hline IntelliArm* & $\mathrm{S}+\mathrm{E}+\mathrm{W}$ & $7 a /(4 a+2 p)$ & $\begin{array}{l}\text { E/D - 1a, } \\
\text { P/R - 2p }\end{array}$ & $\mathrm{e} / \mathrm{c}-\mathrm{d}$ & VR & $\begin{array}{l}\text { Self-alignment (no additional adjustment required), } \\
\text { accurate SG motion, available for both arms }\end{array}$ & $\begin{array}{l}\text { Motors are heavy, no actuation for } \mathrm{P} / \mathrm{R} \text {, singularities } \\
\text { occur }\end{array}$ & no \\
\hline CAREX* & $\mathrm{S}+\mathrm{E}$ & $5 \mathrm{a} / 3 \mathrm{a}$ & no & e/c-d & IMP, AAN & $\begin{array}{l}\text { Lightweight, push/pull forces without rigid links and } \\
\text { joints, actuators remotely located }\end{array}$ & Stationary, no shoulder girdle control & no \\
\hline RUPERT IV* & $\mathrm{S}+\mathrm{E}+\mathrm{W}$ & $5 \mathrm{a} / 2 \mathrm{a}$ & no & PAM & FFC, PID & Lightweight, easily wearable, back-drivable & Limited shoulder movements, slow motion only & yes \\
\hline $\begin{array}{l}\text { Pneu-WREX* } \\
(T-W R E X)\end{array}$ & $\mathrm{S}+\mathrm{E}$ & $5 \mathrm{a} / 4 \mathrm{a}$ & $\mathrm{P} / \mathrm{R}-1 \mathrm{a}$ & $\mathrm{p}$ & $\begin{array}{l}\text { IMP, PD, } \\
\text { AAN }\end{array}$ & $\begin{array}{l}\text { Gravity compensated, control safety systems, visual and } \\
\text { audio feedback }\end{array}$ & Only slow limited movements & yes \\
\hline $\begin{array}{l}\text { LIMPACT * } \\
\text { (Dampace) }\end{array}$ & $\mathrm{S}+\mathrm{E}$ & $4 a /(3 a+2 p)$ & passive & rHEAs & IMP & Self-alignment, gravity compensated & $\begin{array}{l}\text { Expensive installation of its actuation system, } \\
\text { singularities occur }\end{array}$ & no \\
\hline L-EXOS* & $\mathrm{S}+\mathrm{E}+\mathrm{W}$ & $5 \mathrm{a} / 3 \mathrm{a}$ & no & $\mathrm{e} / \mathrm{c}-\mathrm{d}$ & $\begin{array}{l}\text { SMC, IMP } \\
\text { PD }\end{array}$ & $\begin{array}{l}\text { Gravity compensation, low impedance, high payload, } \\
\text { actuators remotely located, improved stiffness }\end{array}$ & Heavy, expensive to manufacture and maintain & yes \\
\hline BONES * & $\mathrm{S}+\mathrm{E}+\mathrm{W}$ & $6 a / 3 a$ & no & $\mathrm{p}$ & AAN & $\begin{array}{l}\text { Parallel structure, allows forearm rotation without the use } \\
\text { of a ring bearing, allows use of large actuators (need not } \\
\text { to be moved), KS considered }\end{array}$ & Reduced workspace, no SG control & yes \\
\hline NTUH-ARM * & $\mathrm{S}+\mathrm{E}$ & $7 \mathrm{a} / 6 \mathrm{a}$ & $\begin{array}{l}\mathrm{E} / \mathrm{D}-1 \mathrm{a} \\
\mathrm{P} / \mathrm{R}-1 \mathrm{a}\end{array}$ & $\mathrm{e}$ & $\begin{array}{l}\text { AAN, IMP, } \\
\text { EMG }\end{array}$ & $\begin{array}{l}\text { Adjustable to various lengths of arm, no circular guide for } \\
\text { shoulder motion, full SG control, two 6-DOF force/torque } \\
\text { sensors, safety issues, KS considered }\end{array}$ & Heavy, redundant design & yes \\
\hline MEDARM & $\mathrm{S}+\mathrm{E}$ & $6 a / 5 a$ & $\begin{array}{l}\mathrm{E} / \mathrm{D}-1 \mathrm{a} \\
\mathrm{P} / \mathrm{R}-1 \mathrm{a}\end{array}$ & $\mathrm{e} / \mathrm{c}-\mathrm{d}$ & - & $\begin{array}{l}\text { Independent monitoring and control of all 5-DOFs of the } \\
\text { shoulder complex }\end{array}$ & $\begin{array}{l}\text { Complex structure, circular approximation of CGH } \\
\text { motion (misalignment occurs), no real prototype } \\
\text { (only Planar 3DOF) }\end{array}$ & no \\
\hline IKO* & $\mathrm{S}+\mathrm{E}+(\mathrm{W})$ & $5 a /(3 a+3 p)$ & passive & hybrid & PI & Self-alignment & Singularities occur & no \\
\hline$\underline{\mathrm{MGA}}$ & $\mathrm{S}+\mathrm{E}+(\mathrm{W})$ & $5 \mathrm{a} / 4 \mathrm{a}$ & $\mathrm{E} / \mathrm{D}-1 \mathrm{a}$ & $\mathrm{e}$ & $\begin{array}{c}\text { IMP, } \\
\text { ADM, PD }\end{array}$ & $\begin{array}{l}\text { Gravity compensation, allows high humerus elevation } \\
\left(147^{\circ}\right)\end{array}$ & $\begin{array}{l}\text { Additional motor, high inertia, not back-drivable, no } \\
\text { actuation for } \mathrm{P} / \mathrm{R} \text { (misalignment occurs) }\end{array}$ & no \\
\hline ASSISTON-SE & $\mathrm{S}+\mathrm{E}$ & $6 a /(5 a+1 p)$ & $\begin{array}{l}\text { E/D - 1a, } \\
\text { P/R - 1a }\end{array}$ & e/SEA & - & $\begin{array}{l}\text { Back-driveable, both passive (slider) and active shoulder } \\
\text { girdle control }\end{array}$ & $\begin{array}{l}\text { Mechanism dimensions and transmission } \\
\text { ratios are not optimized, proposed actuation is not } \\
\text { implemented }\end{array}$ & no \\
\hline
\end{tabular}

UL - upper limb; S - shoulder; E - elbow; W - wrist; E/D - elevation/depression; P/R - protraction/retraction; SG - shoulder girdle; PAM - pneumatic artificial muscles; rHEAs - rotational hydro-elastic actuators; SEA - series elastic actuation; IMP - impedance, PD - proportional derivative; PID - proportional-integral-derivative; CT - computed torque; ADM - admittance; VR - virtual reality based; FFC - feed forward control; EMG - electromyogram based; SMC - sliding mode control; c - coupling; a - active; $\mathrm{p}$-passive, e - electric; c-d - cable-driven, $\mathrm{p}$ - pneumatic; KS - kinematic singularities; sp - stroke patient. *Journal Publication, Highly cited Conference Paper $(>80)$

Table II. Shoulder exoskeletons used in clinical studies

\begin{tabular}{|l|l|l|l|l|}
\hline Device & $\begin{array}{l}\text { Shoulder } \\
\text { DOF }\end{array}$ & Control method & $\begin{array}{l}\text { Patient } \\
\#\end{array}$ & $\begin{array}{l}\text { Clinical } \\
\text { Outcome }\end{array}$ \\
\hline ARMin III & 3 active & IMP, PD, CT & $38 \mathrm{cs}$ & $\uparrow$ FMA \\
\hline ArmeoPower & 3 active & IMP, PD, CT & $35 \mathrm{~s}$ & $\uparrow$ FMA $\uparrow$ MA \\
\hline Pneu-WREX & 4 active & IMP, PD, AAN & $23 \mathrm{cs}$ & $\uparrow F M A ~ \uparrow B B T$ \\
\hline BONES & 3 active & AAN & $20 \mathrm{cs}$ & $\uparrow$ BBT $\uparrow F M A$ \\
\hline EXO-UL7 & 3 active & PID, ADM, EMG & $10 \mathrm{~s}$ & $\uparrow R O M$ \\
\hline L-EXOS & 3 active & IMP, PD & $9 \mathrm{cs}$ & $\uparrow$ FMA $\uparrow M A$ \\
\hline NTUH-ARM & 6 active & AAN & $6 \mathrm{~s}$ & $\uparrow F M A$ \\
\hline c(s) - chronic (stroke); ROM - ranges of motion, \# - number \\
\hline
\end{tabular}


ARAMIS in 50 minute sessions 5 times a week for a duration of 7 weeks [110]. The FMA scores significantly increased for all patients at the end of training process.

RUPERT IV exoskeleton has been tested in two feasibility studies using reaching-out tasks in a $3 \mathrm{D}$ virtual reality environment to validate the effectiveness of a task based robot-assisted repetitive therapy [111]. Six stroke patients were involved in the first study to receive 4 weeks (one-hour session 3 times per week) clinic based robot-assisted therapy and two other patients used this wearable device for the same period on a daily basis at home. The clinical results showed that only few of the involved patients demonstrated improvements and statistical evaluations have shown that only half of the patients trained in clinic had some functional improvement. Both subjects who used RUPERT IV in a home setting showed significant advancements in their performance. However, there is inconsistency in the given results and mainly it is because of the small number of patients involved with a significant variance between their disability levels. Moreover, the duration of these studies might be not long enough to achieve a proper conclusion [111].

There are also other chronic/stroke patient (c/sp) interaction studies reported in the literature with robotic shoulder rehabilitation orthoses such as Pneu-WREX (23 csp) [112], ARMOR (8 sp) [62], ABLE (7 sp) [113], EXO-UL7 (10sp) [114], IntelliArm (3 sp) [45] and MUNDUS (3 SCI and 2 MS) [88].

CAREX has been tested with healthy subjects and one stroke patient. However, more experiments are still needed in order to test larger ranges of $\mathrm{GH}$ joint motions [38]. Experimental evaluations with the HARMONY exoskeleton have demonstrated that the controller produced correct movement for scapulohumeral rhythm and also induced gentle forces when the shoulder exhibited an abnormal rhythmic motion. Some of the other experimental evaluations with healthy subjects (hs) were performed with the following shoulder robotic orthoses: ALEx (6-hs) [58], "Muscle Suit" (5-hs) [78], SUEFUL-7 (2-hs) [57], motion assist robot (2-hs) [64], CADEN-7 (1-hs) [37] and MULOS (1-hs) [69].

Several clinical trials with stroke patients have been conducted using different shoulder exoskeletons. The recent findings of such evaluations have showed some motor function improvements in subjects' upper limb. Moreover, modern technologies like human-robot interfaces with a virtual reality environment, different games and functional exercises boost the intensity of training process, increasing the efficiency of such robotic devices in upper limb rehabilitation. However, more studies with various shoulder exoskeletons are needed involving larger groups of patients with different levels of neurological impairments to confirm their effective physical therapy outcomes. Furthermore, only a few of the existing robotic shoulder orthoses can be tested at home based settings. Table II shows the clinical outcomes of various selected studies with the developed shoulder robotic orthoses, their number of DOFs for shoulder and implemented control strategies. Even though the same assessment measures are mostly used in these trials, the direct comparison is difficult due to differences in patients' disability levels, age and initial evaluation scores, duration of the therapies, study protocols and types of training sessions.

\section{DISCUSSION AND FUTURE DIRECTIONS}

During the last two decades, a large number of robotic shoulder rehabilitation orthoses have been developed to assist people with upper-limb disability and extensive research efforts have been dedicated to advancing the mechanical design and control strategies for such robotic orthoses. This work provides an up to date review of literature with a focus on mechanism design and control for robotic shoulder rehabilitation orthoses. It will be useful to analyze, evaluate and integrate improvements in mechanical mechanisms and control systems of existing devices when designing future shoulder exoskeletons. This will aid in developing a standardized rehabilitation framework for the robot assisted shoulder physical therapy.

The main challenges are that these exoskeletons should be accurately aligned with the human joints, safely adjusted to match different individuals' size and provide naturalistic complex shoulder movements. The robotic shoulder rehabilitation orthoses that take into consideration only three rotational shoulder DOFs provide less workspace for patients and cause discomfort during the training sessions. Hence, to avoid the misalignments between the exoskeleton and human joints and provide larger ranges of motion, shoulder girdle mechanisms should be designed and implemented.

In contrast to designing a mechanism aligned with the human joints, it might be better to consider building an exoskeleton with parallel structure with the same workspace and ranges of motion as the human shoulder [115]. Some shoulder mechanisms with parallel structures are considered in $[41,50,55,75,116,117]$. In fact, robotic devices with parallel structures can be more compact, stiffer, having less inertia and higher load carrying capacity compared to the serial mechanisms [118]. Time spent on the adjustment procedures can also be saved with such parallel shoulder orthoses. However, the drawback of these parallel structures is reduced workspace and mechanical interference between links.

The design of the robotic exoskeletons could be enhanced by using biomechanical principles of human motion [119, 120]. Thus, it is important for robotic specialists to thoroughly study shoulder biomechanics and cooperate with physiologists when designing future robotic orthoses. Understanding the shoulder anatomy and movement characteristics, structure of the bones and articulations, muscle functions and their points of attachments will give a greater perspective towards the development of future robotic rehabilitation orthoses that can stimulate the natural movements of the shoulder complex. New designs of robotic shoulder orthoses should not only reproduce the anatomical structure of shoulder but also integrate its biomechanics, considering the forces and torques at the shoulder complex during the motion of the arm. Hence, it is worth addressing the following questions regarding the physiology of the human shoulder:

- What muscles are involved in common shoulder movements during rehabilitation training?

- What are the forces in these muscles (biarticular muscles) and joint reactions during shoulder movements?

- What neural mechanisms are involved during shoulder rehabilitation therapy? 
- What are the metabolic energy expenditures of the patient with the robotic shoulder orthosis assistance?

In fact, no existing technological components of an actuated machine can outperform the functionality of the human muscles yet. So, the selection of the type of actuation plays one of the major roles in the mechanism design for shoulder robotic rehabilitation orthoses. Electromagnetic actuators, PAM, hydraulic and series elastic actuators have their own inherent advantages and disadvantages. There is always a trade-off between the exoskeleton's functional capacity and weight. After all, the intrinsic elasticity of lightweight PAMs providing compliant actuation makes them a promising technology in the field of rehabilitation robotics actuation.

As all people are different in size and have unique individual body characteristics, adjustable elements and simpler mounting methods are needed. New developments in soft robotics can make the future exoskeletons more flexible so that the structure of the robot will bend with the body and it will be simpler in fitting. Most of the current shoulder orthoses look unappealing to a general public but with the lighter "exosuits" they could be worn underneath the cloth. To overcome the problem caused by the forces added to the body by such soft suits, the future designs should be able to change their frames from solid to soft when needed. The exoskeletons made completely of texture with inflatable parts can be utilized to exchange off material weight and structure. 3D printers using materials with variable mechanical properties can also be used to construct the devices after scanning certain parts of the individual's upper body.

Reducing the cost of the developed shoulder robotic exoskeletons is another important challenge that needs to be overcome by the developers. Current commercial upper limb rehabilitation robots are highly expensive (e.g. ArmeoPower cost 250k EUR [15]). Moreover, their cost does not include the maintenance and physical therapy sessions. The more the already developed commercial products enter the market, conduct clinical studies and increase their sales, the lower will be their final cost. Perhaps, focusing only on a shoulder complex with the optimized robotic orthosis design can bring the cost of the new devices down. Small compact air compressors with replaceable cartridges within the inflatable exoskeletons can also drastically reduce the cost of these upper limb robots. Currently, research teams like Otherlab, San Francisco, rely on high-strength fabric and air power to develop the low cost and lightweight exoskeletons [121]. Better networking between research laboratories and business people, connections to medical and insurance companies, proper regulations and social security are needed to increase the cost-effectiveness of such robotic assistive devices. Finally, rehabilitation robots are not meant to replace the human job but rather to be an effective subset of this job. As the cost of personnel will be rising while the cost of technology will go down, the shoulder robotic exoskeletons will continue to become safer, more reliable and practical.

There is no single recipe for constructing ideal shoulder robotic orthosis. The future shoulder exoskeletons should be safe, compliant, lightweight, adjustable, low-cost and easy to use with user friendly interfaces. Such robotic rehabilitation devices with embedded force and motion sensors will provide more efficient physical therapies to patients with shoulder impairments. A completely wearable, intrinsically compliant shoulder orthoses will be another desirable feature. New control algorithms, advanced electronics, software and machine learning tools will constitute the core of the future research platforms. Research findings in the fields of lower limb rehabilitation, biomechanical modeling, neurophysiology, control systems, mechanism synthesis, and additive manufacturing should also be incorporated in the development of intelligent robotic orthoses for shoulder rehabilitation. To sum up, the further research in robotic shoulder exoskeletons should consider:

- optimum mechanism design for shoulder girdle's main DOFs

- matching the robot's workspace to the entire workspace of the human shoulder taking into account translations of GH joint

- developing an accurate musculoskeletal, kinematic and dynamic models of the human shoulder taking into account all DOFs and ROM of the shoulder complex

- acquiring more experimental/clinical data on the human physiological reaction to mechanical shoulder exoskeleton use

- modelling compliant actuation, designing soft adjustable structures, actuator-brake coupling for gravity compensations, etc.

- employing latest advances in energy harvesting systems: high pressure compressors, fuel cells, flexible batteries, etc.

- developing new faster control algorithms with real time force-feedback controllers in actuation and AAN training strategies.

- collaboration and networking with the researchers from related different fields of study, physiotherapists and industry partners.

Despite the rapid progress in robotic upper limb rehabilitation devices during the last decade, still much remains to be done and we look forward to the innovative contributions that will come about in this exciting area of research.

\section{ACKNOWLEDGMENTS}

This research is supported by the seed funding jointly provided by Faculty of Engineering and Information Sciences, and School of Mechanical, Materials and Mechatronic Engineering, and the $\mathrm{PhD}$ scholarship for the first author funded by the School of Mechanical, Materials and Mechatronic Engineering, University of Wollongong.

\section{REFERENCES}

[1] S. I. Zeferino and D. M. Aycock, "Poststroke shoulder pain: inevitable or preventable?," Rehabilitation Nursing, vol. 35, 2010. 
[2] E. S. Lawrence, C. Coshall, R. Dundas, J. Stewart, A. G. Rudd, R. Howard, et al., "Estimates of the prevalence of acute stroke impairments," Stroke, vol. 32, pp. 1279-1284, 2001.

[3] Z. Adey-Wakeling and M. Crotty, "Upper limb rehabilitation following stroke current evidence and future perspectives," Aging Health, vol. 9, pp. 629-647, 2013.

[4] T. J. Quinn, S. Paolucci, K. S. Sunnerhagen, J. Sivenius, M. F. Walker, D. Toni, et al., "Evidence-based stroke r-ehabilitation: an expanded guidance document from the european stroke organisation (ESO) guidelines for management of ischaemic stroke and transient ischaemic attack 2008," J Rehabil Med, vol. 41, pp. 99-111, Feb 2009.

[5] P. Langhorne, J. Bernhardt, and G. Kwakkel, "Stroke rehabilitation," The Lancet, vol. 377, pp. 1693-1702, 2011.

[6] S. E. Fasoli, H. I. Krebs, J. Stein, W. R. Frontera, and N. Hogan, "Effects of robotic therapy on motor impairment and recovery in chronic stroke," Arch Phys Med Rehabil, vol. 84, pp. 477-82, Apr 2003.

[7] R. Riener, T. Nef, and G. Colombo, "Robot-aided neurorehabilitation of the upper extremities," Med Biol Eng Comput, vol. 43, 2005.

[8] R. Colombo, I. Sterpi, A. Mazzone, C. Delconte, and F. Pisano, "Improving proprioceptive deficits after stroke through robot-assisted training of the upper limb: a pilot case report study," Neurocase, vol. 22, pp. 191-200, Apr 2016.

[9] N. Norouzi-Gheidari, P. S. Archambault, and J. Fung, "Effects of robotassisted therapy on stroke rehabilitation in upper limbs: Systematic review and meta-analysis of the literature," J Rehabil Res Development, vol. 49, p. 479, 2012.

[10] R. A. R. C. Gopura, D. S. V. Bandara, K. Kiguchi, and G. K. I. Mann, "Developments in hardware systems of active upper-limb exoskeleton robots: A review," Robotics and Autonomous Systems, vol. 75, pp. 203$220,2016$.

[11] R. C. V. Loureiro, W. S. Harwin, K. Nagai, and M. Johnson, "Advances in upper limb stroke rehabilitation a technology push," Med Biol Eng Comput, vol. 49, pp. 1103-1118, 2011.

[12] P. Maciejasz, J. Eschweiler, K. Gerlach-Hahn, A. J. Troy, and S. Leonhardt, "A survey on robotic devices for upper limb rehabilitation," $J$ Neuroeng Rehabil, 2014.

[13] N. Jarrasse, T. Proietti, V. Crocher, J. Robertson, A. Sahbani, G. Morel, et al., "Robotic exoskeletons: a perspective for the rehabilitation of arm coordination in stroke patients," Front Hum Neurosci, vol. 8, p. 947, 2014.

[14] H. S. Lo and S. Q. Xie, "Exoskeleton robots for upper-limb rehabilitation: state of the art and future prospects," Med Eng Phys, vol. 34, pp. 261-8, Apr 2012.

[15] G. Turchetti, N. Vitiello, L. Trieste, S. Romiti, E. Geisler, and S. Micera, "Why effectiveness of robot-mediated neurorehabilitation does not necessarily influence its adoption," IEEE Reviews in Biomed Eng, vol. 7, 2014.

[16] M. Babaiasl, S. H. Mahdioun, P. Jaryani, and M. Yazdani, "A review of technological and clinical aspects of robot-aided rehabilitation of upperextremity after stroke," Disabil Rehabil Assist Technol, vol. 11, pp. 263 80, May 2016.

[17] R. J. Sanchez, D. J. Reinkensmeyer, P. Shah, J. Liu, S. Rao, R. Smith, et al., "Monitoring functional arm movement for home-based therapy after stroke," in 26th Annual Int. Conf. IEEE EMBS, San Franciso, CA, USA, 2004.

[18] A. H. A. Stienen, E. E. G. Hekman, G. B. Prange, M. J. A. Jannink, A M. M. Aalsma, F. C. T. van der Helm, et al., "Dampace: Design of an Exoskeleton for Force-Coordination Training in Upper-Extremity Rehabilitation," J Medical Devices, vol. 3, p. 031003, 2009.

[19] H. I. Krebs, M. Ferraro, S. P. Buerger, M. J. Newbery, A. Makiyama, M. Sandmann, et al., "Rehabilitation robotics: pilot trial of a spatial extension for MIT-Manus," J Neuroeng Rehabil, vol. 1, p. 5, Oct 26 2004.

[20] C. Hogfors, G. Sigholm, and P. Herrerts, "Biomechanical model of the human shoulder - i. Elements," J Biomech, vol. 20, pp. 157-166, 1987.

[21] J. Lenarcic and M. Stanisic, "A humanoid shoulder complex and the humeral pointing kinematics," IEEE Trans Robot Autom, vol. 19, 2003.

[22] J. Hamill and K. M. Knutzen, "Functional Anatomy," in Biomechanical Basis of Human Movement, ed, 2007, p. 137.

[23] H. E. Veeger and F. C. van der Helm, "Shoulder function: the perfect compromise between mobility and stability," J Biomech, vol. 40, pp 2119-29, 2007.

[24] J. Hurov, "Anatomy and mechanics of the shoulder: review of current concepts," J Hand Ther, vol. 22, pp. 328-42; quiz 343, Oct-Dec 2009.
[25] R. Lugo, P. Kung, and C. B. Ma, "Shoulder biomechanics," Eur J Radiol, vol. 68, pp. 16-24, Oct 2008.

[26] N. Klopcar and J. Lenarcic, "Bilateral and unilateral shoulder girdle kinematics during humeral elevation," Clin Biomech (Bristol, Avon), vol. 21 Suppl 1, pp. S20-6, 2006.

[27] F. C. Forte, M. P. de Castro, J. M. de Toledo, D. C. Ribeiro, and J. F. Loss, "Scapular kinematics and scapulohumeral rhythm during resisted shoulder abduction--implications for clinical practice," Phys Ther Sport, vol. 10, pp. 105-11, Aug 2009.

[28] P. M. Ludewig, V. Phadke, J. P. Braman, D. R. Hassett, C. J. Cieminski, and R. F. LaPrade, "Motion of the shoulder complex during multiplanar humeral elevation," J Bone Joint Surg Am, vol. 91, pp. 378-89, Feb 2009.

[29] D. Koo, P. H. Chang, M. K. Sohn, and J. Shin, "Shoulder mechanism design of an exoskeleton robot for stroke patient rehabilitation," presented at the IEEE Int. Conf. Rehabil. Robot., Zurich, Switzerland, 2011.

[30] S. J. Ball, "Novel robotic mechanisms for upper-limb rehabilitation and assessment," PhD, Queen's University, 2008.

[31] T. Nef and R. Riener, "ARMin - design of a novel arm rehabilitation robot," in IEEE 9th Int. Conf. Rehabil. Robot., Chicago, IL, USA, 2005.

[32] M. Mihelj, T. Nef, and R. Riener, "ARMin II - 7 DoF rehabilitation robot mechanics and kinematics," presented at the IEEE Int. Conf. Robotics and Automation, Roma, Italy, 2007.

[33] T. Nef, M. Guidali, and R. Riener, "ARMin III - arm therapy exoskeleton with an ergonomic shoulder actuation," Applied Bionics and Biomechanics, vol. 6, pp. 127-142, 2009.

[34] T. Nef and R. Riener, "Shoulder Actuation Mechanisms for Arm Rehabiliation Exoskeletons," in 2nd Biennial IEEE/RAS-EMBS Int. Conf. Biomed. Robot. Biomechatronics, Scottsdale, AZ, USA, 2008.

[35] T. Nef, R. Riener, R. Muri, and U. P. Mosimann, "Comfort of two shoulder actuation mechanisms for arm therapy exoskeletons: a comparative study in healthy subjects," Med Biol Eng Comput, vol. 51, pp. 781-9, Jul 2013.

[36] C. Carignan, J. Tang, and S. Roderick, "Development of an exoskeleton haptic interface for virtual task training," presented at the Int. Conf. Intelligent Robots and Systems, St. Louis, USA, 2009.

[37] J. C. Perry, J. Rosen, and B. S., "Upper-Limb Powered Exoskeleton Design," IEEE/ASME Trans Mechatronics, vol. 12, 2007.

[38] Y. Mao, D. G.G., S. J.P., and S. K. Agrawal, "Human Movement Training With a Cable Driven ARm EXoskeleton (CAREX)," IEEE Trans Neural Syst Rehabil Eng, vol. 23, 2015.

[39] C. Carignan, M. Liszka, and S. Roderick, "Design of an arm exoskeleton with scapula motion for shoulder rehabilitation," in 12th Int. Conf. Advanced Robotics, 2005., Seattle, WA, 2005.

[40] L. K. Miller and J. Rosen, "Comparison of multi-sensor admittance control in joint space and task space for a seven degree of freedom upper limb exoskeleton," in 3rd IEEE RAS \& EMBS Int. Conf. Biomed. Robot. Biomechatronics, The University of Tokyo, Tokyo, Japan, 2010.

[41] Y. Mao and S. K. Agrawal, "Design of a Cable-Driven Arm Exoskeleton (CAREX) for Neural Rehabilitation," IEEE Trans Robotics, vol. 29, 2012.

[42] G. Yang, H. L. Ho, and W. Chen, "A Haptic Device Wearable on a Human Arm," in IEEE Conf. Robot. Autom. Mechatronics, Singapore, 2004.

[43] Y. Mao and S. K. Agrawal, "A Cable Driven Upper Arm Exoskeleton for Upper Extremity Rehabilitation," presented at the IEEE Int. Conf. Robotics and Automation, Shanghai, China, 2011.

[44] H. S. Park, Y. Ren, and L. Zhang, "IntelliArm an exoskeleton for diagnosis and treatment of patients with neurological impairments," in 2nd Biennial Int. Conf. Biomed. Robot. Biomechatronics, Scottsdale, AZ, USA, 2008.

[45] Y. Ren, S. H. Kang, H. S. Park, Y. N. Wu, and L. Q. Zhang, "Developing a Multi-Joint Upper Limb Exoskeleton Robot for Diagnosis, Therapy, and Outcome Evaluation in Neurorehabilitation," IEEE Trans Neural Syst Rehabil Eng, vol. 21, 2013.

[46] J.-H. Park, K.-S. Lee, H. Lee, and H. S. Park, "Development of a passive shoulder joint tracking device for upper limb rehabilitation robots," presented at the IEEE Int. Conf. Rehabil. Robot., Singapore, 2015.

[47] S. H. Chen, W. M. Lien, W. W. Wang, G. D. Lee, L. C. Hsu, K. W. Lee, et al., "Assistive Control System for Upper Limb Rehabilitation Robot," IEEE Trans Neural Syst Rehabil Eng, Feb 242016.

[48] H. Yan, C. Yang, Y. Zhang, and Y. Wang, "Design and Validation of a Compatible 3-Degrees of Freedom Shoulder Exoskeleton With an Adaptive Center of Rotation," J Mech Design, vol. 136, p. 071006, 2014. 
[49] S. J. Ball, I. E. Brown, and S. H. Scott, "MEDARM: a rehabilitation robot with 5DOF at the shoulder complex," presented at the IEEE/ASME Int. Conf. Adv. Intelligent Mechatronics, Zurich, 2007.

[50] M. A. Ergin and V. Patoglu, "ASSISTON-SE: A Self-Aligning Shoulder-Elbow Exoskeleton," presented at the IEEE Int. Conf. Robotics and Automation, St. Paul, Minnesota, USA, 2012.

[51] S. Balasubramanian, R. Wei, M. Perez, B. Shepard, E. Koeneman, J. Koeneman, et al., "RUPERT: An Exoskeleton Robot for Assisting Rehabilitation of Arm Functions," presented at the Virtual Rehabilitation, Vancouver, BC, 2008

[52] E. T. Wolbrecht, V. Chan, D. J. Reinkensmeyer, and J. E. Bobrow, "Optimizing compliant, model-based robotic assistance to promote neurorehabilitation," IEEE Trans Neural Syst Rehabil Eng, vol. 16, 2008.

[53] A. Otten, C. Voort, A. Stienen, R. Aarts, E. Asseldonk, and H. Kooij, "LIMPACT: A hydraulically powered self-aligning upper limb exoskeleton," IEEE/ASME Trans Mechatronics, vol. 20, 2015.

[54] B. Kim and A. D. Deshpande, "Controls for the Shoulder Mechanism of an Upper-Body Exoskeleton for Promoting Scapulohumeral Rhythm," presented at the IEEE Int. Conf. Rehabil. Robot., 2015.

[55] J. Hunt, H. Lee, and P. Artemiadis, "A Novel Shoulder Exoskeleton Robot Using Parallel Actuation and a Passive Slip Interface," Journal of Mechanisms and Robotics, vol. 9, p. 011002, 2016.

[56] A. Frisoli, F. Rocchi, S. Marcheschi, A. Dettory, F. Salsedo, and M. Bergamasco, "A new force-feedback arm exoskeleton for haptic interaction in Virtual Environments," in 1st Joint Eurohaptics Conf. and Symp. Haptic Interf. Virt. Envir. Teleop. Sys., 2005.

[57] R. A. R. C. Gopura, K. Kiguchi, and Y. Li, "SUEFUL-7: A 7dof upperlimb exoskeleton robot with muscle-model-oriented emg-based control," presented at the IEEE/RSJ Int. Conf. Intelligent Robots and Systems, St. Louis, USA, 2009.

[58] E. Pirondini, M. Coscia, S. Marcheschi, G. Roas, F. Salsedo, A. Frisoli, et al., "Evaluation of the effects of the Arm Light Exoskeleton on movement execution and muscle activities: a pilot study on healthy subjects," J Neuroeng Rehabil, vol. 13, p. 9, 2016.

[59] S. H. Scott, "Apparatus for measuring and perturbing shoulder and elbow joint positions and torques during reaching," J Neuroscience Methods, vol. 89, pp. 119-127, 1999

[60] M. H. Rahman, T. Kittel-Ouimet, M. Saad, J. P. Kenne, and P. S Archambault, "Development and control of a robotic exoskeleton for shoulder, elbow and forearm movement assistance," Applied Bionics and Biomechanics, vol. 9, pp. 275-292, 2012.

[61] L. Colizzi, A. Lidonnici, and L. Pignolo, "The ARAMIS project: a concept robot and technical design," J Rehabil Med, vol. 41, pp. 1011101, Nov 2009.

[62] A. Mayr, M. Kofler, and L. Saltuari, "ARMOR: an electromechanical robot for upper limb training following stroke. A prospective randomised controlled pilot study," Handchir Mikrochir plast Chir, vol. 40, pp. 6673, 2008.

[63] F. Martinez, A. Pujana-Arrese, I. Retolaza, I. Sacristan, J. Basurko, and J. Landaluze, "IKO: a five actuated DoF upper limb exoskeleton oriented to workplace assistance," Applied Bionics and Biomechanics, vol. 6, pp. 143-155, 2009.

[64] K. Kiguchi, M. H. Rahman, M. Sasaki, and K. Teramoto, "Development of a 3DOF mobile exoskeleton robot for human upper-limb motion assist," Robotics and Autonomous Systems, vol. 56, pp. 678-691, 2008.

[65] Z. Li, Z. Huang, W. He, and C.-Y. Su, "Adaptive Impedance Control for an Upper Limb Robotic Exoskeleton Using Biological Signals," IEEE Trans Ind Electron, pp. 1-1, 2016.

[66] P. Letier, M. Avraam, S. Veillerette, M. Horodinca, M. Bartolomei, A. Schiele, et al., "SAM a 7-dof portable arm exoskeleton with local joint control," presented at the IEEE/RSJ Int. Conf. Intelligent Robotis and Systems, Nice, France, 2008

[67] J.-Y. Kim, U.-J. Yang, and K. Park, "Design, motion planning and control of frozen shoulder rehabilitation robot," Int J Prec Eng Manuf, vol. 15, pp. 1875-1881, 2014.

[68] P. Garrec, J. P. Friconneau, Y. Measson, and Y. Perrot, "ABLE, an innovative transparent exoskeleton for the upper-limb," presented at the IEEE/RSJ Int. Conf. Intelligent Robots and Systems, Nice, France, 2008.

[69] G. R. Johnson, D. A. Carus, G. Parrini, S. S. Marchese, and R. Valeggi, "The design of a 5DOF powered orthosis for the upper limb," IMechE, vol. $215,2001$.

[70] T. G. Sugar, J. He, E. Koeneman, J. B. Koeneman, R. Herman, H. Huang, et al., "Design and Control of RUPERT: A Device for Robotic
Upper Extremity Repetitive Therapy," IEEE Trans Neural Syst Rehabil Eng, vol. 15, 2007.

[71] J. Huang, X. Tu, and J. He, "Design and evaluation of the rupert wearable upper extremity exoskeleton robot for clinical and in-home therapies," IEEE Trans Syst Man Cybern, 2015.

[72] R. Morales, F. J. Badesa, N. Garcia-Aracil, J. M. Sabater, and C. PerezVidal, "Pneumatic robotic systems for upper limb rehabilitation," Med Biol Eng Comput, vol. 49, pp. 1145-56, Oct 2011.

[73] R. J. Sanchez, E. T. Wolbrecht, R. Smith, J. Liu, S. Rao, S. C. Cramer, et al., "A pneumatic robot for re-training arm movement after stroke rationale and mechanical design," in IEEE 9th Int. Conf. Rehabil. Robot., Chicago, IL, USA, 2005.

[74] R. J. Sanchez, J. Liu, S. Rao, P. Shah, R. Smith, T. Rahman, et al., "Automating Arm Movement Training Following Severe Stroke Functional Exercises With Quantitative Feedback in a Gravity-Reduced Environment," IEEE Trans Neural Syst Rehabil Eng, vol. 14, 2006.

[75] J. Klein, S. Spencer, J. Allington, J. E. Bobrow, and D. J. Reinkensmeyer, "Optimization of a parallel shoulder mechanism to achieve a high-force, low-mass, robotic-arm exoskeleton," IEEE Trans Robotics, vol. 26, 2010.

[76] S. Ikemoto, Y. Kimoto, and K. Hosoda, "Shoulder complex linkage mechanism for humanlike musculoskeletal robot arms," Bioinspir Biomim, vol. 10, p. 066009, Dec 2015.

[77] N. G. Tsagarakis and D. G. Caldwell, "Development and Control of a 'Soft-Actuated' Exoskeleton for Use in Physiotherapy and Training," Autonomous Robots, vol. 15, pp. 21-33, 2003.

[78] H. Kobayashi and K. Hiramatsu, "Development of Muscle Suit for Upper Limb," in IEEE Int. Conf. Robotics and Automation, New Orleans, LA, 2004.

[79] J. Zhang, "Novel 6-Dof wearable exoskeleton arm with pneumatic forcefeedback for bilateral teleoperation," Chinese J Mech Eng (English Edition), vol. 21, p. 58, 2008.

[80] Y. S. Kim, J. Lee, S. Lee, and M. Kim, "A force reflected exoskeletontype masterarm for human-robot interaction," IEEE Trans Syst Man Cybern, vol. 35, 2005

[81] Y. Jeong, Y. Lee, K. Kim, Y.-S. Hong, and P. J.-O., "A 7 DOF Wearable Robotic Arm Using Pneumatic Actuators," in 32nd Int. Symp. Robotics, 2001

[82] T. Noda and J. Morimoto, "Development of Upper-extremity Exoskeleton driven by Pneumatic Cylinder toward Robotic Rehabilitation Platform for Shoulder Elevation," presented at the IEEE Int. Conf. Rehabil. Robot., Singapore, 2015.

[83] A. Stienen, E. Hekman, H. Braak, A. M. M. Aalsma, F. C. Van der Helm, and H. van der Kooij, "Design of a rotational hydroelastic actuator for a powered exoskeleton for upper limb rehabilitation," IEEE Trans Biomed Eng, vol. 57, 2010.

[84] M. Mistry, P. Mohajerian, and S. Schaal, "Arm movement experiments with joint space force fields using an Exoskeleton Robot," in IEEE 9th Int. Conf. Rehabil. Robot., Chicago, IL, USA, 2005.

[85] I. Galiana, F. L. Hammond, R. D. Howe, and M. B. Popovic, "Wearable Soft Robotics Device for Post-Stroke Shoulder Rehabilitation: Identifying Misalignments," presented at the IEEE/RSJ Int. Conf. Intelligent Robotics and Systems, Vilamoura, Algarva, Portugal, 2012.

[86] K. Xu, Y. Wang, and Z. Yang, "Design and Preliminary Experimentation of a Continuum Exoskeleton for Self-Provided Bilateral Rehabilitation," presented at the IEEE Int. Conf. Inform. Autom., Hailar, China, 2014.

[87] H.-C. Hsieh, L. Chien, and C.-C. Lan, "Mechanical Design of a GravityBalancing Wearable Exoskeleton for the Motion Enhancement of Human Upper Limb," presented at the IEEE Int. Conf. Robotics and Automation, Seattle, Washington 2015.

[88] P. A. e. al, "MUNDUS project MUltimodal Neuroprosthesis for daily Upper limb Support," J Neuroeng and Rehabil, vol. 10, 2013.

[89] Y. Jung and J. Bae, "Kinematic analysis of a 5-dof upper-limb exoskeleton with a tilted and vertically translating shoulder joint," IEEE/ASME Trans Mechatronics vol. 20, 2015.

[90] R. Vertechy, A. Frisoli, A. Dettori, M. Solazzi, and M. Bergamasco, "Development of a new exoskeleton for upper limb rehabilitation," presented at the IEEE 11 th Int. Conf. Rehabil. Robot., Kyoto, Japan, 2009.

[91] L. Marchal-Crespo and D. J. Reinkensmeyer, "Review of control strategies for robotic movement training after neurologic injury," $J$ Neuroeng Rehabil, vol. 6, p. 20, 2009.

[92] H. B. Kang and J. H. Wang, "Adaptive control of 5 DOF upper-limb exoskeleton robot with improved safety," ISA Trans, vol. 52, pp. 844-52, Nov 2013. 
[93] S. Oh, K. Kong, and Y. Hori, "Design and Analysis of Force-SensorLess Power-Assist Control," IEEE Trans Ind Electron, vol. 61, 2014.

[94] Z. Tang, K. Zhang, S. Sun, Z. Gao, L. Zhang, and Z. Yang, "An upperlimb power-assist exoskeleton using proportional myoelectric control," Sensors (Basel), vol. 14, pp. 6677-94, 2014.

[95] K. Anam and A. A. Al-Jumaily, "Active exoskeleton control systems: State of the art," Procedia Engineering, vol. 41, pp. 988-994, 2012.

[96] A. Basteris, S. M. Nijenhuis, A. Stienen, J. H. Buurke, G. B. Prange, and F. Amirabdollahian, "Training modalities in robot-mediated upper limb rehabilitation in stroke: a framework for classification based on a systematic review," J Neuroeng Rehabil, vol. 11, 2014.

[97] C. Sicuri and G. Porcellini, "Robotics in shoulder rehabilitation," Muscles, Ligaments and Tendos Journal, vol. 4, pp. 207-213, 2014.

[98] T. Proietti, V. Crocher, A. Roby-Brami, and N. Jarrasse, "Upper-limb robotic exoskeletons for neurorehabilitation: a review on control strategies," IEEE Reviews in Biomed Eng, 2016.

[99] A. U. Pehlivan, "Design and Control of an Exoskeletal Rehabilitation Device for Stroke and Spinal Cord Injury Patients," Master of Science, Rice University, 2011.

[100]W. Yu, J. Rosen, and X. Li, "PID Admittance Control for an Upper Limb Exoskeleton," presented at the American Control Conference, San Francisco, CA, USA, 2011.

[101]T. Kashima and K. Hori, "Control of biomimetic robots based on analysis of human arm trajectories in 3D movements," Artificial Life and Robotics, vol. 21, pp. 24-30, 2015.

[102]M. Babaiasl, A. Ghanbari, and S. Noorani, "Anthropomorphic mechanical design and Lyapunov-based control of a new shoulder rehabilitation system," Eng Solid Mech, vol. 2, pp. 151-162, 2014.

[103]S. Balasubramanian and J. He, "Adaptive Control of a Wearable Exoskeleton for Upper-Extremity Neurorehabilitation," Applied Bionics and Biomechanics, vol. 9, pp. 99-115, 2012.

[104]M. H. Rahman, C. Ochoa-Luna, and M. Saad, "EMG Based Control of a Robotic Exoskeleton for Shoulder and Elbow Motion Assist," J Autom Control Eng, pp. 270-276, 2015.

[105]P. Staubli, T. Nef, V. Klamroth-Marganska, and R. Riener, "Effects of intensive arm training with the rehabilitation robot ARMin II in chronic stroke patients: four single-cases," J Neuroeng Rehabil, vol. 6, p. 46, 2009.

[106]V. Klamroth-Marganska, J. Blanco, K. Campen, A. Curt, V. Dietz, T. Ettlin, et al., "Three-dimensional, task-specific robot therapy of the arm after stroke: a multicentre, parallel-group randomised trial," The Lancet Neurology, vol. 13, pp. 159-166, 2014.

[107]R. S. Calabro, M. Russo, A. Naro, D. Milardi, T. Balletta, A. Leo, et al., "Who may benefit from armeo power treatment? A neurophysiological approach to predict neurorehabilitation outcomes," PM R, Feb 202016.

[108]M.-H. Milot, S. Spencer, V. Chan, J. Allington, J. Klein, C. Chou, et al., "A crossover pilot study evaluating the functional outcomes of two different types of robotic movement training in chronic stroke survivors using the arm exoskeleton BONES," J Neuroeng Rehabil, vol. 10, 2013.

[109]A. Frisoli, C. Procopio, C. Chisari, I. Creatini, L. Bonfiglio, M. Bergamasco, et al., "Positive effects of robotic exoskeleton training of upper limb reaching movements after stroke," J Neuroeng Rehabil, vol. 9, p. 36, 2012.

[110]L. Pignolo, G. Dolce, G. Basta, L. F. Lucca, S. Serra, and W. G. Sannita, "Upper limb rehabilitation after stroke: ARAMIS a "robomechatronic" innovative approach and prototype," presented at the 4th RAS/EMBS Int. Conf. Biomed. Robotics and Biomechatronics, Roma, Italy, 2012.

[111]H. Zhang, H. Austin, S. Buchanan, R. Herman, J. Koeneman, and J. He, "Feasibility Studies of Robot-Assisted Stroke Rehabilitation at Clinic and Home Settings Using RUPERT," presented at the IEEE Int. Conf. Rehabil. Robot., Zurich, Switzerland, 2011.

[112]D. J. Reinkensmeyer, E. T. Wolbrecht, V. Chan, C. Chou, S. C. Cramer, and J. E. Bobrow, "Comparison of 3D, assist-as-needed robotic arm/hand movement training provided with pneu-wrex to conventional table top therapy following chronic stroke," Am J Phys Med Rehabil, vol. 91, pp. 232-241, 2012.

[113]V. Crocher, A. Sahbani, J. Robertson, A. Roby-Brami, and G. Morel, "Constraining upper limb synergies of hemiparetic patients using a robotic exoskeleton in the perspective of nuero-rehabilitation," IEEE Trans Neural Syst Rehabil Eng, vol. 20, 2012

[114]M. Simkins, H. Kim, G. Abrams, N. Byl, and J. Rosen, "Robotic unilateral and bilateral upper-limb movement training for stroke survivors afflicted by chronic hemiparesis," presented at the IEEE Int Conf. Rehab. Robot., Seattle, Washington, USA, 2013.
[115]A. Schiele and F. C. Van der Helm, "Kinematic design to improve ergonomics in human machine interaction," IEEE Trans Neural Syst Rehabil Eng, vol. 14, 2006.

[116]D. Ingram, C. Engelhardt, A. Farron, A. Terrier, and P. Müllhaupt, "Modelling of the human shoulder as a parallel mechanism without constraints," Mechanism and Machine Theory, vol. 100, pp. 120-137, 2016.

[117]Y. Chen, G. Li, Y. Zhu, J. Zhao, and H. Cai, "Design of a 6-DOF upper limb rehabilitation exoskeleton with parallel actuated joints," Biomed Mater Eng, vol. 24, pp. 2527-35, 2014

[118]A. Shintemirov, A. Niyetkaliyev, and M. Rubagotti, "Numerical Optimal Control of a Spherical Parallel Manipulator Based on Unique Kinematic Solutions," IEEE/ASME Trans Mechatronics, vol. 21, 2016.

[119]D. P. Ferris, G. S. Sawicki, and M. A. Daley, "A physiologist's perspective on robotic exoskeletons for human locomotion," Int $J \mathrm{HR}$, vol. 4, pp. 507-528, 2007.

[120]A. A. Biewener and M. A. Daley, "Unsteady locomotion: integrating muscle function with whole body dynamics and neuromuscular control," J Exp Biol, vol. 210, pp. 2949-60, Sep 2007.

[121] Exoskeleton Report. Exoskeleton Report. [online] Available at: http://exoskeletonreport.com [Accessed 19 Jan. 2017].

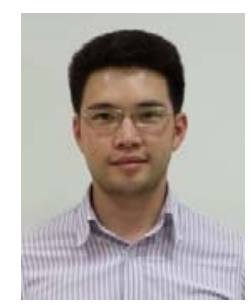

Aibek Niyetkaliyev received the B.Sc. degree in aerospace engineering with a minor in mathematics from Texas A\&M University, USA, in 2011, and the M.Sc. degree in mechanics from Eurasian National University, Kazakhstan, in 2015. He is currently pursuing $\mathrm{PhD}$ degree in Rehabilitation Robotics at the University of Wollongong, Australia. His research interests include robot-assisted rehabilitation, biomechanical modeling, design, kinematics and control of robot manipulators.

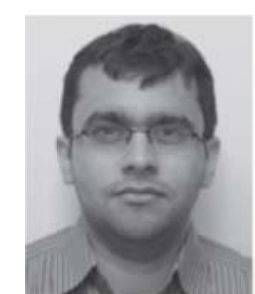

Shahid Hussain received the B.Sc. degree (with honors) in mechatronics and control engineering from the University of Engineering and Technology Lahore, Pakistan, in 2007, the M.E. and Ph.D degree in mechanical engineering from The University of Auckland, New Zealand, in 2009 and 2013, respectively. He is a lecturer at the University of Wollongong, Australia. His research interests include robot-assisted rehabilitation, compliant actuation of robots, human-robot interaction, biomechanical modeling of musculoskeletal system and nonlinear control of dynamic systems.

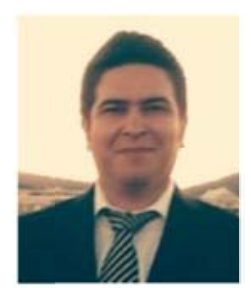

Mergen H. Ghayesh received the Ph.D. degree in mechanical engineering from the Department of Mechanical Engineering, McGill University, Montreal, QC, Canada, in 2013. He is an Assistant Professor with the School of Mechanical Engineering, University of Adelaide. His research interests include machine dynamics and mechanisms, system dynamics and control, dynamics of micro/nano-electro-mechanical systems, motionbased energy harvesters, flow induced dynamics, and dynamical behavior of biomechanical organs.

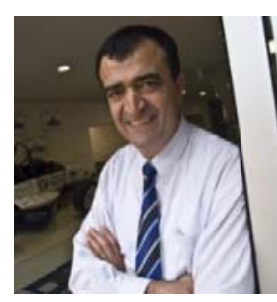

Gursel Alici received the Ph.D. degree in robotics from the Department of Engineering Science, Oxford University, Oxford, U.K., in 1994. He is currently a Senior Professor at the University of Wollongong, Australia, where he is the Head of the School of Mechanical, Materials, Mechatronic and Biomedical Engineering since 2011. His research interests are soft robotics, system dynamics and control, robotic drug delivery systems, novel actuation concepts for biomechatronic applications, robotic mechanisms and manipulation systems, soft and smart actuators and sensors, and medical robotics. He has generated more than 300 refereed publications, and delivered numerous invited seminars and keynote talks on his areas of research. 